\section{Cdc7-Drf1 is a developmentally regulated protein kinase required for the initiation of vertebrate DNA replication}

\author{
Tatsuro S. Takahashi and Johannes C. Walter ${ }^{1}$ \\ Department of Biological Chemistry and Molecular \\ Pharmacology, Harvard Medical School, \\ Boston, Massachusetts 02115, USA
}

Cdc7, a protein kinase required for the initiation of eukaryotic DNA replication, is activated by a regulatory subunit, Dbf4. A second activator of Cdc7 called Drf1 exists in vertebrates, but its function is unknown. Here, we report that in Xenopus egg extracts, Cdc7-Drf1 is far more abundant than Cdc7-Dbf4, and removal of Drf1 but not Dbf4 severely inhibits phosphorylation of $\mathrm{Mcm} 4$ and DNA replication. After gastrulation, when the cell cycle acquires somatic characteristics, Drf1 levels decline sharply and Cdc7-Dbf4 becomes the more abundant kinase. These results identify Drf1 as a developmentally regulated, essential activator of $\mathrm{Cdc} 7$ in $\mathrm{Xeno}$ pus.

Supplemental material is available at http://www.genesdev.org.

Received June 2, 2005; revised version accepted August 3, 2005.

Eukaryotic chromosomal DNA replication initiates via the ordered recruitment of replication proteins onto chromatin (for review, see Bell and Dutta 2002). In the G1 phase, ORC, Cdc6, and Cdt1 cooperate to load the Mcm2-7 complex onto chromatin, resulting in formation of the prereplication complex (pre-RC). The Mcm2-7 complex is believed to be the replicative DNA helicase (for review, see Takahashi et al. 2005). Activation of the Mcm2-7 helicase at the G1/S transition is a crucial step for initiation, which requires multiple factors, including Cdc7 protein kinase as well as Cdc45, a likely helicase cofactor (Pacek and Walter 2004).

Accumulating evidence suggests that a crucial substrate of the Cdc7-kinase is the Mcm2-7 complex. Mcm2, Mcm3, Mcm4, and Mcm6 are in vitro substrates of the Cdc7-kinase in yeast and humans (Lei et al. 1997; Sato et al. 1997; Brown and Kelly 1998; Jiang et al. 1999; Kumagai et al. 1999; Weinreich and Stillman 1999; Masai et al. 2000; Lee et al. 2003). In Xenopus and yeast, phosphorylation of $\mathrm{Mcm} 2$ on chromatin during replication is dependent on Cdc7 (Lei et al. 1997; Jares and Blow 2000; Takeda et al. 2001). Finally, in budding yeast, a point mutation in $\mathrm{Mcm} 5$ renders Cdc7-Dbf4 dispensable for viability, further pointing to $\mathrm{Mcm} 2-7$ as a crucial

[Keywords: Cdc7; Drf1; Dbf4; DNA replication; Xenopus; developmental regulation]

${ }^{1}$ Corresponding author.

E-MAIL johannes walter@hms.harvard.edu; FAX (617) 738-0516.

Article and publication are at http://www.genesdev.org/cgi/doi/10.1101/ gad.1339805
Cdc7 target (Hardy et al. 1997). However, functionally important Cdc7 phosphorlation sites remain to be identified.

The activity of Cdc7-kinase is regulated by an activator subunit, Dbf4. Cdc7-Dbf4 has therefore been referred to as DDK (Dbf4-dependent kinase) (for review, see Johnston et al. 1999). Recently a Dbf4-related protein, Drf1, was found in humans and Xenopus (Montagnoli et al. 2002; Yanow et al. 2003; Yoshizawa-Sugata et al. 2005), and the question arises as to why vertebrates contain two regulators of Cdc7. In Xenopus, Dbf4 activates the Cdc7-kinase in vitro, and recombinant Cdc7-Dbf4 can stimulate DNA replication when added to Xenopus egg extracts (Jares and Blow 2000; Furukohri et al. 2003; Shechter et al. 2004a). However, attempts to address the role of Dbf4 in DNA replication in egg extracts were confounded by nonspecific inhibition of DNA replication by the Dbf4 antibodies used (Jares et al. 2004). In turn, depletion of Drf1 showed no effect on DNA replication (Yanow et al. 2003). Therefore, the regulatory subunit that accounts for the essential role of Cdc7 (Jares and Blow 2000; Walter 2000) in Xenopus eggs remains elusive. In humans, both Dbf4 (also called ASK) and Drf1 (also called ASKL1) activate Cdc7-kinase in vitro (Jiang et al. 1999; Kumagai et al. 1999; Montagnoli et al. 2002; Yoshizawa-Sugata et al. 2005). In human tissue culture cells, inhibition of Dbf4 via antibody interference blocks DNA replication, whereas inhibition of Drf1 via RNA interference (RNAi) slows S-phase progression (Kumagai et al. 1999; Yoshizawa-Sugata et al. 2005). Collectively, the available data suggest that Dbf4 may have a more important role for the initiation of DNA replication than Drf1, but the precise functions of Dbf4 and Drf1 have not been determined.

In this article, we compared directly the properties of Cdc7-Drf1 and Cdc7-Dbf4 in Xenopus egg extracts and during early Xenopus development. The data support the surprising conclusion that Cdc7-Drf1 plays a far more prominent role than Cdc7-Dbf4 in promoting DNA replication during the early embryonic cell cycles.

\section{Results and Discussion}

To study the mechanism of DNA replication in Xenopus egg extracts, we use two related systems which differ in their requirement for nuclear envelope assembly (Supplementary Fig. S1). In the nucleus-dependent system, sperm chromatin is added to a low speed supernatant (LSS) of egg cytoplasm, leading to pre-RC formation, nuclear envelope assembly, and DNA replication. In the nucleus-independent system, a high-speed supernatant (HSS) of egg cytoplasm that is depleted of membrane precursors stimulates pre-RC formation on added DNA templates (plasmid or sperm chromatin). Subsequent addition of a nucleoplasmic extract (NPE) stimulates DNA replication in the absence of nuclear envelope assembly.

We raised antibodies against Xenopus Dbf4 and Drf1 and examined their abundance in egg extracts. Both antibodies recognized phosphorylated and unphosphorylated forms of their respective antigen in LSS and NPE (Fig. 1A). Densitometric quantification of Western blots demonstrated that the concentration of Drf1 in LSS is 22 $\mathrm{nM}$, whereas the concentration of Dbf4 is only $1.2 \mathrm{nM}$ (Supplementary Fig. S2A,B). Furthermore, Drf1 is en- 


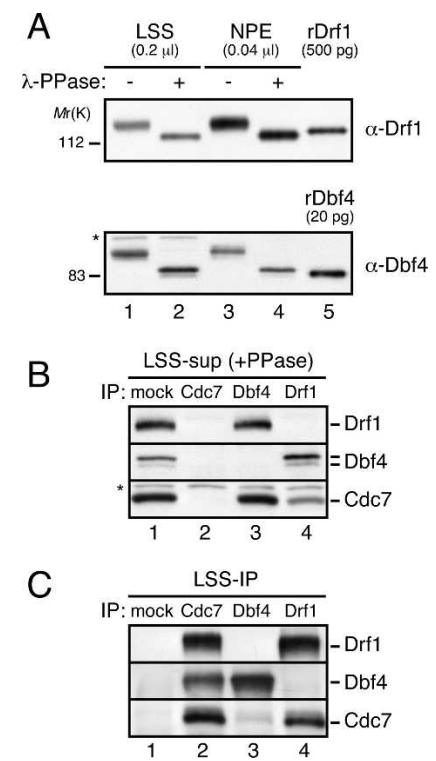

Figure 1. Cdc7-Drf1 is far more abundant than Cdc7-Dbf4 in Xenopus egg extracts. $(A)$ Characterization of anti-Drf1 and Dbf4 antibodies: $0.2 \mu \mathrm{L}$ LSS (lane 1), $0.2 \mu \mathrm{L} \lambda$-protein phosphatase-treated LSS (lane 2), $0.04 \mu \mathrm{L}$ NPE (lane 3), and $0.04 \mu \mathrm{L} \lambda$-protein phosphatase-treated NPE (lane 4) were separated by SDS-PAGE and probed with anti-Drf1 (top panel) or Dbf4 (bottom panel) antibodies alongside $500 \mathrm{pg}$ of recombinant Drf1 (6xHis and StrepII-tagged) (lane 5, top panel) or $20 \mathrm{pg}$ recombinant Dbf4 (6xHis-tagged) (lane 5, bottom panel). Asterisks indicate cross-reacting bands. $(B, C) \mathrm{Cdc} 7 \mathrm{com}-$ plexes were immunoprecipitated from LSS by control (lane 1), antiCdc7 (lane 2), anti-Dbf4 (lane 3), or anti-Drf1 (lane 4) antibodies, and the supernatant $(B)$ and immunoprecipitate $(C)$ fractions were probed with antibodies against Drf1 (top panels), Dbf4 (middle panels), and Cdc7 (bottom panels). Cross-reacting bands (*) serve as loading controls. In $B$ and later figures involving Dbf 4 blotting of LSS, extracts were treated with phosphatase due to a cross-reacting band migrating with phosphorylated Dbf4.

riched $\sim 12$-fold in NPE relative to LSS, whereas Dbf4 is enriched only threefold (Supplementary Fig. S2C). Consistent with this different degree of nuclear enrichment, the concentrations of Drf1 and Dbf4 in NPE were estimated as 260 and $3.6 \mathrm{nM}$, respectively (Supplementary Fig. S2B). Thus, Drf1 is $\sim 18$-fold more abundant in LSS and $\sim 70$-fold more abundant in NPE than Dbf4 (results summarized in Supplementary Table S1).

We next examined the relative abundance of Cdc7Dbf4 and Cdc7-Drf1 complexes in egg extracts using reciprocal immunoprecipitation (IP). IP of Cdc7 removed all detectable Drf1 and Dbf4 from extracts, showing that all the Drf1 and Dbf4 associate with Cdc7 (Fig. 1B,C, lane 2). Conversely, IP of Dbf4 coprecipitated only a small amount of Cdc7 (Fig. 1B,C, lane 3), whereas IP of Drf1 removed $\sim 70 \%$ of Cdc7 from LSS (Fig. 1B,C, lane 4). Therefore, the majority of Cdc7 is in a complex with Drf1. The data indicate that the concentration of Cdc7Drf1 and Cdc7-Dbf4 are essentially the same as that of each regulatory subunit, $22 \mathrm{nM}$ and $1.2 \mathrm{nM}$, respectively. About $30 \%$ of Cdc7 remained in the supernatant after Dbf4-Drf1 double depletion, indicating that $30 \%$ of Cdc 7 $(\sim 9 \mathrm{nM})$ binds neither Drf1 nor Dbf4 in LSS (see Fig. 4D, below). We obtained essentially the same results in NPE, except that the ratio was further biased in favor of Cdc7Drf1 (Supplementary Fig. S3). In summary, Cdc7-Drf1 is by far the predominant form of DDK in Xenopus egg extracts, especially in nuclei, where DNA replication takes place.

Due to its high abundance, we revisited the role of Cdc7-Drf1 in DNA replication. As shown in Figure 2, depletion of Drf1 reduced the initial rate of DNA replication approximately sevenfold compared with the mock depletion. Addition of recombinant Cdc7-Drf1 (rCdc7-Drf1) to the depleted extract at $40 \mathrm{nM}$ final concentration restored replication to nearly control levels (Fig. 2, filled circles), whereas rCdc7-Drf1 did not significantly enhance DNA replication of the mock-depleted extract (Fig. 2, open circles). Furthermore, we found that recombinant Drf1 alone could rescue DNA replication in Drf1-depleted LSS (Supplementary Fig. S4). This result is consistent with data presented in Figure 1, which indicate that a significant fraction of Cdc7 (30\% in LSS) is not bound to any known regulatory subunits. Our data show that Cdc7-Drf1 is specifically required for efficient DNA replication in Xenopus egg extracts. Previous attempts to functionally deplete Drf1 from LSS (Yanow et al. 2003) were likely unsuccessful due to the high concentration of this protein present in the extract.

Previous results showed that immunodepletion of Cdc7 impairs replication initiation, since origin unwinding, chromatin loading of $\mathrm{Cdc} 45$, and $\mathrm{Mcm} 2$ phosphorylation are reduced (Jares and Blow 2000; Walter 2000). To determine whether Drf1 is required for replication initiation, we performed an origin unwinding assay in the nucleus-free replication system (Walter and Newport 2000). Thus, when DNA replication is initiated on a circular plasmid in the presence of the DNA polymerase inhibitor aphidicolin, an Mcm2-7-dependent helicase is uncoupled from the replication fork and a highly unwound form of the plasmid called U-form DNA is generated (Pacek and Walter 2004; Shechter et al. 2004b). While mock-depleted HSS and NPE supported hyper-unwinding, extracts depleted of Drf1 did not (Fig. 3A, cf. lanes 3-5 and 9-11). The complete absence of U-form DNA is consistent with the fact that Drf1 depletion completely blocked replication in NPE (data not show). Importantly, rCdc7-Drf1 restored generation of U-form DNA (Fig. 3A, lanes 12-14). These data indicate that Cdc7-Drf1 is required for activation of the replicative DNA helicase.

We next asked whether Cdc7-Drf1 is required for chromatin loading of Cdc45. Compared with the mockdepleted control, Drf1 depletion significantly impaired Cdc45 loading onto sperm chromatin in LSS, and rCdc7-

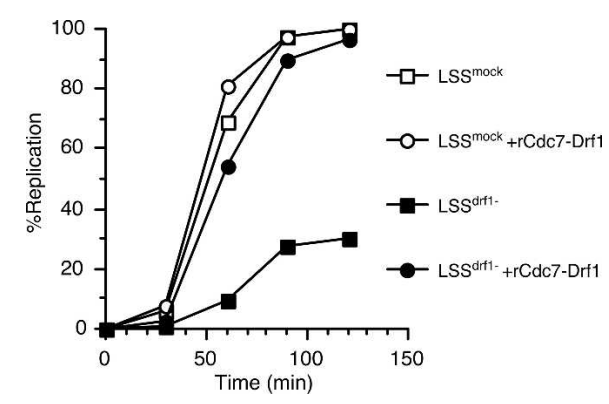

Figure 2. Drf1 is required for DNA replication. Sperm chromatin was incubated in mock-depleted LSS supplemented with buffer (open squares) or $40 \mathrm{nM}$ rCdc7-Drf1 (open circles), or Drf1-depleted LSS supplemented with buffer (filled squares) or $40 \mathrm{nM}$ rCdc7-Drf1 (filled circles). 
A
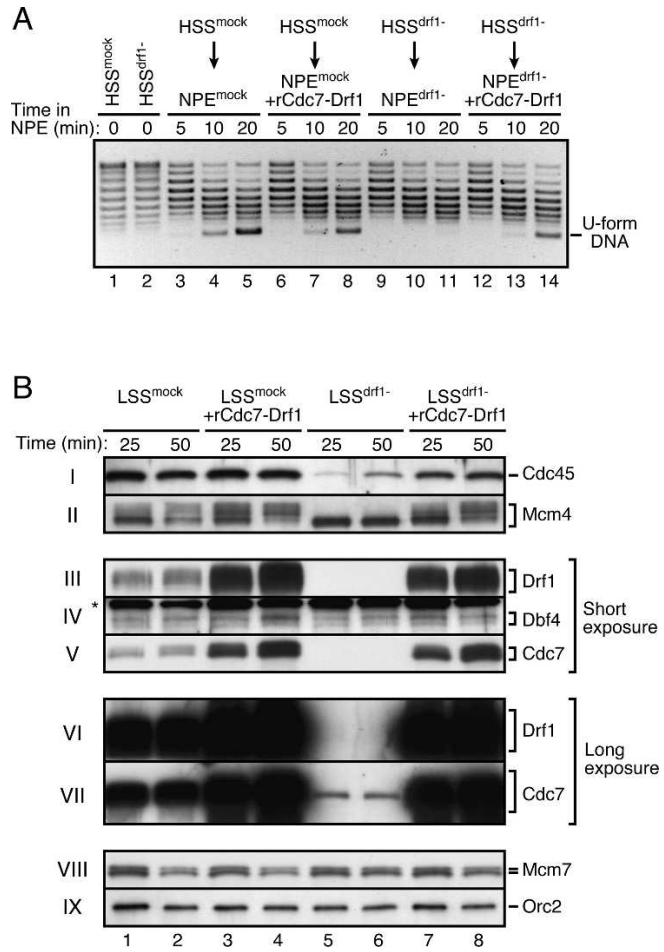

Figure 3. Cdc7-Drf1 is required for initiation of DNA replication. (A) Drf1 is required for origin unwinding. pBluescriptII was incubated in mock-depleted (lane 1) or Drf1-depleted (lane 2) HSS at 40 $\mathrm{ng} / \mu \mathrm{L}$ concentration for $30 \mathrm{~min}$ and isolated, or further incubated in mock-depleted (lanes 3-8) or Drf1-depleted (lanes 9-14) NPE containing $50 \mu \mathrm{g} / \mathrm{mL}$ aphidicolin and buffer (lanes 3-5,9-11) or $500 \mathrm{nM}$ rCdc7-Drf1 (lanes 6-8,12-14). At the indicated times, the plasmid topology was analyzed by agarose gel electrophoresis in the presence of $1.8 \mu \mathrm{M}$ chloroquine. (B) Requirement of Drf1 for Mcm4 phosphorylation and Cdc45 loading. Sperm chromatin was incubated in mock-depleted (lanes 1-4) or Drf1-depleted (lanes 5-8) LSS containing buffer (lanes 1,2,5,6) or $50 \mathrm{nM}$ rCdc7-Drf1 (lanes 3,4,7,8) and recovered through a sucrose cushion at the indicated time points. Bound proteins were eluted and analyzed by Western blotting using the indicated antibodies. $\left(^{*}\right)$ Cross-reacting band.

Drf1 reversed the loading defect (Fig. 3B, panel I). Mcm7 and Orc2 served as loading controls (Fig. 3B, panels VIII,IX). These data are consistent with a previous report in which Drf1 depletion caused reduction of Cdc45 loading, even though no inhibition of DNA replication was observed (Yanow et al. 2003).

A highly phosphorylated form of Mcm4 has been described and shown to accumulate on chromatin at the G1/S transition in Xenopus egg extracts independently of Cdk2 activity (Pereverzeva et al. 2000). Since purified Cdc7 can phosphorylate yeast and human Mcm4 proteins (Lei et al. 1997; Weinreich and Stillman 1999; Masai et al. 2000; Lee et al. 2003), we speculated that Mcm4 hyperphosphorylation in Xenopus egg extracts is Cdc7Drf1 dependent. We first confirmed previous results (Pereverzeva et al. 2000) that the slower migrating forms of Mcm4 are due to phosphorylation (Supplementary Fig. S5A, lanes 2,4). Figure 3B shows that the appearance of hyperphosphorylated Mcm4 was greatly reduced by Drf1 depletion, and the effect was reversed by rCdc7-Drf1 (panel II, lanes 5-8). Moreover, addition of rCdc7-Drf1 to the mock-depleted extract enhanced Mcm 4 phosphorylation, further suggesting that Cdc7-Drf1 is involved in
Mcm4 phosphorylation (Fig. 3B, panel II, lanes 3,4). Finally, we show that Mcm4 phosphorylation correlates closely with Cdc7-Drf1 chromatin loading, and that it immediately precedes Cdc45 recruitment (Supplementary Fig. S5B). The results are consistent with the idea that Cdc7-Drf1-dependent phosphorylation of Mcm4 is an important step in Cdc45 recruitment to chromatin.

As shown previously (Yanow et al. 2003), Drf1 depletion also inhibited chromatin association of Cdc7 (Fig. 3B, panels III, V, lanes 5,6). However, chromatin association of Dbf4 was unaffected by Drf1 depletion, indicating that chromatin binding of Cdc7-Dbf4 is independent of Cdc7-Drf1 (Fig. 3B, panel IV, cf. lanes 1,2 and 5,6). Consistent with this, we detected weak binding of Cdc 7 but not Drf1 in a longer exposure of the same membrane (Fig. 3B, panels VI,VII), and this residual Cdc7 binding was Dbf4 dependent, since it was absent in extracts depleted of Drf1 and Dbf4 (data not shown).

We next addressed whether Cdc7-Dbf4 is required for DNA replication in Xenopus egg extracts. Our Dbf4 antibodies removed at least $99 \%$ of Dbf4 from LSS (Fig. 4A), reducing the Dbf4 concentration to at most $\sim 12 \mathrm{pM}$. However, there was no significant effect on DNA replication (Fig. 4B), Mcm4 phosphorylation (Fig. 4C), or the chromatin loading of Cdc45, Drf1, or Cdc7 (Fig. 4C). Assuming that replication initiation occurs approximately every $10 \mathrm{~kb}$ on sperm chromatin $\left(3 \times 10^{9} \mathrm{bp}\right)$, in our experimental conditions $(3000 \mathrm{sperm} / \mathrm{\mu L})$, there are $9 \times 10^{8}$ origins per microliter extract. At a concentration of 12 $\mathrm{pM}$, there is only one Cdc7-Dbf4 complex available for approximately every 125 origins that are normally activated. The effective concentration of Cdc7-Dbf4 is probably even lower, since only $\sim 10 \%$ of Dbf 4 normally localizes to nuclei (see Supplementary Table S1). Since it is unlikely that a single Cdc7-Dbf4 complex could rapidly activate $\gg 100$ origins, the data suggest that Cdc7-Dbf4 is not normally required for DNA replication in Xenopus egg extracts.

To test whether Dbf4 might account for the residual DNA replication observed in Drf1-depleted extracts, we depleted Drf1 and Dbf4 simultaneously and compared replication with Drf1-depleted extracts. Western blotting showed that all detectable Dbf4 and Drf1 were removed by the double depletion (Fig. 4D). As shown above, Drf1 depletion significantly reduced DNA replication (Fig. 4E, filled squares), but codepletion of Dbf4 caused no further decrease (Fig. 4E, filled triangles), suggesting that the residual replication activity seen in Drf1-depleted extracts is not due to Dbf4. It is possible that the remaining DNA replication seen in Drf1/Dbf4depleted extracts is due to a third Cdc7 regulatory subunit that remains to be identified, or to a low level of Cdc7-independent origin firing. Interestingly, as is the case for Drf1, depletion of Cdc7 resulted in extracts that supported residual DNA replication (data not shown). However, as for Drf1 depletion, we are unable to determine whether this residual replication is due to trace amounts of $\mathrm{Cdc} 7$ remaining in the extract, or due to a low level of Cdc7-independent origin firing.

Since Dbf4 depletion had no effect on DNA replication in any context, the question arose whether Xenopus Cdc7-Dbf4 has the capacity to stimulate DNA replication. Previous results showed that addition of Cdc7Dbf4 to mock-depleted or Cdc7-depleted egg extracts could boost DNA replication (Jares et al. 2004; Shechter et al. 2004a). Consistent with this, Figure 4F shows that 
A

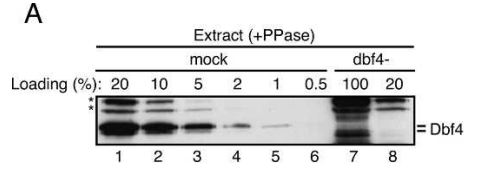

D

B



C

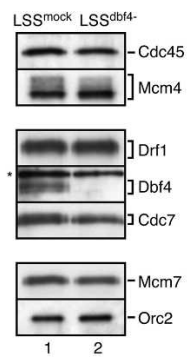



$\mathrm{E}$

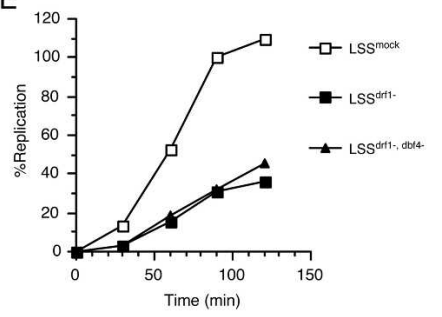

$\mathrm{F}$

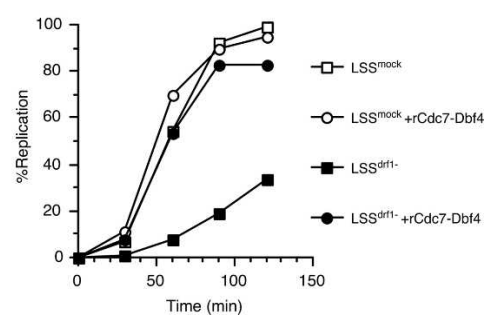

Figure 4. Dbf4 is not required for DNA replication in Xenopus egg extracts. $(A)$ The indicated amounts of mock-depleted (lanes 1-6) or Dbf4-depleted (lanes 7,8) LSS treated with $\lambda$-protein phosphatase were separated on SDS-PAGE and probed with anti-Dbf4 antibody; $100 \%=1 \mu \mathrm{L}$. Cross-reacting bands ( ${ }^{*}$ ) serve as loading controls. (B) Replication efficiency in the mock-depleted (open squares) or Dbf4depleted (filled squares) LSS shown in $A$. (C) Sperm chromatin was incubated in mock-depleted (lane 1) or Dbf4-depleted (lane 2) LSS in the presence of $50 \mu \mathrm{g} / \mathrm{mL}$ aphidicolin and isolated after $45 \mathrm{~min}$. Western blotting for the indicated proteins is presented. ( ${ }^{\star}$ ) Cross-reacting band. In $D, 0.2 \mu \mathrm{L}$ each of mock-depleted (lane 1), Drf1-depleted (lane 2), or Drf1/Dbf4-depleted (lane 3) LSS was treated with $\lambda$-protein phosphatase, separated by SDS-PAGE, and probed for the indicated proteins. ${ }^{*}$ ) Cross-reacting band. (E) Replication efficiency in mock-depleted (open squares), Drf1-depleted (filled squares), and Drf1- and Dbf4-depleted (filled triangles) LSS shown in $D$. (F) Replication efficiency in LSS that was mock-depleted (open squares), Drf1-depleted (filled squares), mock-depleted and supplemented with $1 \mu \mathrm{M}$ recombinant Cdc7-Dbf4 (open circles), and Drf1-depleted and supplemented with $1 \mu \mathrm{M}$ recombinant Cdc7-Dbf4 (filled circles).

the defect in DNA replication caused by Drf1 depletion was completely reversed by recombinant Cdc7-Dbf4 complex. Therefore, while Cdc7-Dbf4 has the ability to promote DNA replication, endogenous Cdc7-Dbf4 in Xenopus egg extracts does not appear to contribute to DNA replication, probably due to its very low concentration, and possibly due to inefficient nuclear transport (Supplementary Table S1) and/or chromatin binding (Fig. 3B).

To extend the comparison between Dbf4 and Drf1, we examined how they are recruited to chromatin. Like Drf1 (Yanow et al. 2003), and in contrast to previous reports (Furukohri et al. 2003; Jares et al. 2004), Dbf4 bound to chromatin in a manner that was pre-RC-dependent (Supplementary Fig. S6). Moreover, like Dbf4 (Jares et al. 2004), Drf1 was essential to recruit Cdc7 to chromatin (Supplementary Fig. S7). Therefore, both Drf1 and Dbf4 not only function as Cdc7 activating proteins, but also recruit $\mathrm{Cdc} 7$ to its likely site of action, the pre-RC.

Our data indicate that in Xenopus egg extracts, Cdc7Drf1 is critical for DNA replication while Cdc7-Dbf4 is dispensable, yet antibody injection experiments suggest that Dbf4 is essential for DNA replication in somatic cells (Kumagai et al. 1999). One way to reconcile these findings would be if the contributions to DNA replication of Drf1 and Dbf4 were developmentally regulated, being inverted between embryonic and somatic cells. To test this possibility, we asked whether levels of Cdc7Drf1 and Cdc7-Dbf4 change during development.

Upon fertilization, Xenopus eggs undergo 12 rapid, $\sim 25$-min cell divisions which lack gap phases. Following the 12 th division, at a time known as the mid-blastula transition (MBT), the cell cycle is extended and becomes asynchronous, and zygotic transcription starts (Newport and Kirschner 1982a,b). Three divisions after the $\mathrm{MBT}$, at the early-gastrula transition (EGT), maternal mRNAs are degraded and zygotic transcription assumes control of the cell cycle (Newport and Dasso 1989; Howe et al. 1995). As a result, the cell cycle is dramatically expanded and it takes on somatic characteristics.

To examine Cdc7-Drf1 and Cdc7-Dbf4 levels during development, we fertilized eggs in vitro. Embryos were collected at the indicated time points and staged (Nieuwkoop and Faber 1967), and Cdc7 was immunoprecipitated. Cdc7 recovery was similar at all developmental stages (Fig. 5A). Cdc7, Drf1, and Dbf4 were all hypermodified in meiotically arrested eggs (Fig. 5A, lane 1). Intriguingly, Cdc7-associated Drf1 levels began to drop just before the onset of gastrulation (stage 9), when the cell cycle becomes somatic in nature, and they became undetectable at the neurula stage (stage 20). Conversely, levels of Dbf4 associated with Cdc7 gradually went up during the first $12 \mathrm{~h}$ of development, and they further increased significantly between 12 and $24 \mathrm{~h}$, during which time all detectable Cdc7-Drf1 disappeared.

For a more quantitative comparison of Cdc7Dbf4 and Cdc7-Drf1 levels during development, we performed reciprocal IPs using Cdc7, Dbf4, and Drf 1 antibodies at stages 3 and 11 . As seen above, IP of Cdc7 at stage 3 coprecipitated significant amounts of Drf1 (Fig. 5B, lane 2). Conversely, IP of Drf1 precipitated most of the Cdc7, as seen by comparison with the amount of Cdc7 recovered in the Cdc7-IP (Fig. $5 \mathrm{~B}$, cf. lanes 4 and 2). In contrast, IP of Dbf4 precipitated only a small amount of Cdc7 at this stage (Fig. 5B, lane 3). Therefore, Cdc7-Drf1 is still the predominant DDK at stage 3 . At stage 11, IP of Cdc7 coprecipitated far less Drf 1 and a significantly greater amount of Dbf4 than at stage 3 (Fig. 5B, cf. lanes 6 and 2). Moreover, at this stage, Dbf4 coprecipitated slightly more Cdc7 than did Drf1, indicating that the concentration of Cdc7-Dbf4 is now greater than Cdc7-Drf1 (Fig. 5B, lanes 7,8). Western blotting of the total extracts revealed that the IPs removed the vast majority of each target protein, and that the total level of Drf1 severely decreased, while that of Dbf4 significantly increased between stage 3 and stage 11 (Supplementary Fig. S8). Together, these results argue that the ratio of Cdc7-Drf1 and Cdc7-Dbf4 undergoes a reversal after gastrulation.

In summary, our data indicate that Cdc7-Drf1 plays an essential role in DNA replication in the early embryonic cell cycles. Given the ability of Drf1 to support DNA 
A



B

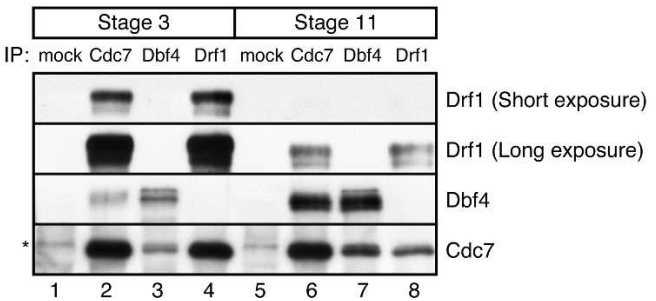

Figure 5. Developmental regulation of Drf1 and Dbf4. (A) Unfertilized Xenopus eggs (lane 1) or in vitro fertilized Xenopus embryos (lanes 2-13) were isolated at the indicated time points and staged according to Nieuwkoop and Faber (1967). Cdc7 complexes were immunoprecipitated from embryo lysates with anti-Cdc7 antibody and probed for Drf1 (top and second panels), Dbf4 (third and fouth panels), and Cdc7 (bottom panel). (B) Stage 3 in vitro fertilized Xenopus embryos (lanes 1-4) or stage 11 embryos (lanes 5-8) were collected and used for immunoprecipitation with control (lanes 1,5), anti-Cdc7 (lanes 2,6), anti-Dbf4 (lanes 3,7), and anti-Drf1 (lanes 4,8) antibodies. Western blotting for the indicated proteins is presented. An asterisk shows the IgG heavy chain, which reacts with the secondary antibody.

replication, we propose that DDK stand for "Dbf4- and Drf1-dependent protein kinase." The regulatory subunits of Cdc7 appear to provide at least two functions: activation of $\mathrm{Cdc} 7$ kinase and localization of $\mathrm{Cdc} 7$ to the pre- $\mathrm{RC}$, where the substrate of Cdc7 presumably resides. Our results identify $\mathrm{Mcm} 4$ as an excellent potential substrate for Cdc7-Drf1 during replication in Xenopus egg extracts, since Mcm4 hyperphosphorylation is Cdc7Drf1 dependent, and it coincides with the chromatin loading of Cdc7-Drf1. Moreover, Mcm4 hyperphosphorylation immediately precedes Cdc45 loading (Supplementary Fig. S5B). Thus, phosphorylation of Mcm4 by Cdc7-Drf1 could explain the requirement for Cdc7-Drf1 in Cdc45 loading. A rigorous test of this model must await identification and mutation of Cdc7Drf1 phosphorylation sites within Mcm4.

Our data raise the question of which DDK complex is required for DNA replication in somatic cells. The rise in Cdc7-Dbf4 abundance after gastrulation suggests that this kinase might predominate in somatic cells. However, no quantitative comparisons of Dbf4 and Drf1 expression levels have been reported in specific primary tissues, and in the absence of genetic experiments, it is unclear which DDK stimulates DNA replication after early development. In transformed human tissue culture cells, Dbf4 and Drf1 are much more highly expressed than in most primary tissues (Kumagai et al. 1999; Montagnoli et al. 2002), and in HeLa cells, antibody injection experiments indicate that Dbf4 is essential for DNA rep- lication (Kumagai et al. 1999). When Drf1 expression is knocked down by RNAi in U2OS cells, there is a detectable slowing of progression through $\mathrm{S}$ phase, consistent with our data that Drf1 can function in DNA replication (Yoshizawa-Sugata et al. 2005). Although the lack of a more dramatic effect may be due to the relatively inefficient Drf1 knockdown, another interpretation is that Dbf4 is the more important regulatory subunit in transformed cells. Clearly, further work is needed to assess the relative roles of the two DDKs in primary and transformed somatic cells.

Our work and previous data suggest that Cdc7-Drf1 and Cdc7-Dbf4 share key characteristics: Both complexes can stimulate DNA replication (Figs. 2, 4F; Jares et al. 2004; Shechter et al. 2004a), both are recruited to pre-RCs via their regulatory subunits (Supplementary Figs. S6, S7; Jares et al. 2004), and both are able to phosphorylate Mcm2 in vitro (Furukohri et al. 2003; Yanow et al. 2003). Moreover, the fact that rCdc7-Dbf4 completely rescued replication in a Drf1-depleted extract suggests that Cdc7-Drf1 is not uniquely capable of driving a rapid embryonic S phase. Why then did Drf1 evolve? One possible difference between the two regulators might involve their response to checkpoints. Etoposide, a topoisomerase II inhibitor, arrests replication initiation and induces dissociation of Dbf4, but not Drf1, from Cdc7 (Costanzo et al. 2003; Yanow et al. 2003). These data suggest that Cdc7-Drf1 is resistant to inhibition by certain cell cycle checkpoints, a property that might be important to establish rapid embryonic cell cycles that are refractory to arrest. An alternative hypothesis is that the two DDKs have evolved to deal with different forms of chromatin structure. Cdc7-Drf1 might be designed to facilitate efficient initiation from the open, nontranscribed chromatin present in the embryo, while Cdc7-Dbf4 may be better suited for the highly compacted chromatin seen in somatic cells.

\section{Materials and methods}

Extracts, DNA replication, and chromatin binding

Extract preparation, replication assays, and chromatin-binding assays in the nucleus-free replication system were carried out as described (Walter et al. 1998; Walter and Newport 2000). Sperm nuclei were incubated in HSS at 10,000/pL in all experiments. In LSS (Blow 1993), sperm nuclei were incubated at $3000 / \mu \mathrm{L}$ in all experiments, and chromatin isolation and replication were carried out as described previously (Takahashi et al. 2004). The amount of DNA synthesis was calculated using the method described by Blow and Laskey (1986), which takes into account the concentration of endogenous dNTPs. Endogenous dNTP concentration was measured for each fresh extract, and for immunodepleted extracts, this number was multiplied by 0.8 , the experimentally determined dilution factor that results from the immunodepletion procedure. For phosphatase treament, $1 \mu \mathrm{L}$ of extract was incubated with $400 \mathrm{U}$ of $\lambda$-protein phosphatase (New England Biolabs) in $10 \mu \mathrm{L}$ of $\lambda$-phosphatase buffer (New England Biolabs) containing $2 \mathrm{mM} \mathrm{MnCl}{ }_{2}$ at $30^{\circ} \mathrm{C}$ for $30 \mathrm{~min}$. Other experimental procedures are described in the Supplemental Material.

\section{Acknowledgments}

We thank William G. Dunphy for the Drfl cDNA, John Newport for Mcm4 antiserum, Vladimir Joukov for a Xenopus cDNA library, and Yasuko Onuma for technical advice on developmental experiments. Thanks to Emily Arias, Markus Raschle, Gernot Walter, Matt Michael, and Elaine Elion for helpful comments on the manuscript. T.S.T. is a recipient of a post-doctoral fellowship for research abroad from the Japan Society for the Promotion of Science (2004). This work was supported by NIH grant GM62267 to J.C.W. 


\section{References}

Bell, S.P. and Dutta, A. 2002. DNA replication in eukaryotic cells. Annu. Rev. Biochem. 71: 333-374.

Blow, J.J. 1993. Preventing re-replication of DNA in a single cell cycle: Evidence for a replication licensing factor. I. Cell. Biol. 122: 993 1002.

Blow, J.J. and Laskey, R.A. 1986. Initiation of DNA replication in nuclei and purified DNA by a cell-free extract of Xenopus eggs. Cell 47: 577-587.

Brown, G.W. and Kelly, T.J. 1998. Purification of Hsk1, a minichromosome maintenance protein kinase from fission yeast. J. Biol. Chem. 273: 22083-22090.

Costanzo, V., Shechter, D., Lupardus, P.J., Cimprich, K.A., Gottesman, M., and Gautier, J. 2003. An ATR- and Cdc7-dependent DNA damage checkpoint that inhibits initiation of DNA replication. Mol. Cell 11: 203-213.

Furukohri, A., Sato, N., Masai, H., Arai, K., Sugino, A., and Waga, S. 2003. Identification and characterization of a Xenopus homolog of Dbf4, a regulatory subunit of the $\mathrm{Cdc} 7$ protein kinase required for the initiation of DNA replication. J. Biochem. (Tokyo) 134: 447-457.

Hardy, C.F., Dryga, O., Seematter, S., Pahl, P.M., and Sclafani, R.A. 1997. $\mathrm{mcm} 5 / \mathrm{cdc} 46$-bob1 bypasses the requirement for the $\mathrm{S}$ phase activator Cdc7p. Proc. Natl. Acad. Sci. 94: 3151-3155.

Howe, J.A., Howell, M., Hunt, T., and Newport, J.W. 1995. Identification of a developmental timer regulating the stability of embryonic cyclin A and a new somatic A-type cyclin at gastrulation. Genes \& Dev. 9: 1164-1176.

Jares, P. and Blow, J.J. 2000. Xenopus cdc7 function is dependent on licensing but not on XORC, XCdc6, or CDK activity and is required for XCdc45 loading. Genes \& Dev. 14: 1528-1540.

Jares, P., Luciani, M.G., and Blow, J.J. 2004. A Xenopus Dbf4 homolog is required for $\mathrm{Cdc} 7$ chromatin binding and DNA replication. BMC Mol. Biol. 5: 5 .

Jiang, W., McDonald, D., Hope, T.J., and Hunter, T. 1999. Mammalian Cdc7-Dbf4 protein kinase complex is essential for initiation of DNA replication. EMBO J. 18: 5703-5713.

Johnston, L.H., Masai, H., and Sugino, A. 1999. First the CDKs, now the DDKs. Trends Cell. Biol. 9: 249-252.

Kumagai, H., Sato, N., Yamada, M., Mahony, D., Seghezzi, W., Lees, E., Arai, K., and Masai, H. 1999. A novel growth- and cell cycle-regulated protein, ASK, activates human Cdc7-related kinase and is essential for G1/S transition in mammalian cells. Mol. Cell. Biol. 19: 50835095.

Lee, J.K., Seo, Y.S., and Hurwitz, J. 2003. The Cdc23 (Mcm10) protein is required for the phosphorylation of minichromosome maintenance complex by the Dfp1-Hsk1 kinase. Proc. Nat1. Acad. Sci. 100: 2334 2339.

Lei, M., Kawasaki, Y., Young, M.R., Kihara, M., Sugino, A., and Tye, B.K. 1997. Mcm2 is a target of regulation by Cdc7-Dbf4 during the initiation of DNA synthesis. Genes \& Dev. 11: 3365-3374.

Masai, H., Matsui, E., You, Z., Ishimi, Y., Tamai, K., and Arai, K. 2000. Human Cdc7-related kinase complex: In vitro phosphorylation of MCM by concerted actions of Cdks and Cdc7 and that of a criticial threonine residue of Cdc7 bY Cdks. J. Biol. Chem. 275: 29042-29052.

Montagnoli, A., Bosotti, R., Villa, F., Rialland, M., Brotherton, D., Mercurio, C., Berthelsen, J., and Santocanale, C. 2002. Drf1, a novel regulatory subunit for human Cdc7 kinase. EMBO I. 21: 3171-3181.

Newport, J. and Dasso, M. 1989. On the coupling between DNA replication and mitosis. J. Cell. Sci. Suppl. 12: 149-160.

Newport, J. and Kirschner, M. 1982a. A major developmental transition in early Xenopus embryos, I: Characterization and timing of cellular changes at the midblastula stage. Cell 30: 675-686.

- 1982b. A major developmental transition in early Xenopus embryos, II: Control of the onset of transcription. Cell 30: 687-696.

Nieuwkoop, P.D. and Faber, J. 1967. Normal table of Xenopus laevis. North-Holland Publishing, Amsterdam, The Netherlands.

Pacek, M. and Walter, J.C. 2004. A requirement for MCM7 and Cdc45 in chromosome unwinding during eukaryotic DNA replication. EMBO J. 23: 3667-3676.

Pereverzeva, I., Whitmire, E., Khan, B., and Coue, M. 2000. Distinct phosphoisoforms of the Xenopus Mcm4 protein regulate the function of the Mcm complex. Mol. Cell. Biol. 20: 3667-3676.
Sato, N., Arai, K., and Masai, H. 1997. Human and Xenopus cDNAs encoding budding yeast Cdc7-related kinases: In vitro phosphorylation of MCM subunits by a putative human homologue of Cdc7. EMBO T. 16: 4340-4351.

Shechter, D., Costanzo, V., and Gautier, J. 2004a. ATR and ATM regulate the timing of DNA replication origin firing. Nat. Cell. Biol. 6: 648655.

Shechter, D., Ying, C.Y., and Gautier, J. 2004b. DNA unwinding is an Mcm complex-dependent and ATP hydrolysis-dependent process. I. Biol. Chem. 279: 45586-45593.

Takahashi, T.S., Yiu, P., Chou, M.F., Gygi, S., and Walter, J.C. 2004 Recruitment of Xenopus Scc2 and cohesin to chromatin requires the pre-replication complex. Nat. Cell. Biol. 6: 991-996.

Takahashi, T.S., Wigley, D.B., and Walter, J.C. 2005. Pumps, paradoxes and ploughshares: Mechanism of the MCM2-7 DNA helicase. Trends Biochem. Sci. 30: 437-444.

Takeda, T., Ogino, K., Tatebayashi, K., Ikeda, H., Arai, K., and Masai, H. 2001. Regulation of initiation of S phase, replication checkpoint signaling, and maintenance of mitotic chromosome structures during S phase by Hsk1 kinase in the fission yeast. Mol. Biol. Cell. 12: 12571274.

Walter, J.C. 2000. Evidence for sequential action of cdc7 and cdk2 protein kinases during initiation of DNA replication in Xenopus egg extracts. J. Biol. Chem. 275: 39773-39778.

Walter, J. and Newport, J. 2000. Initiation of eukaryotic DNA replication: Origin unwinding and sequential chromatin association of Cdc45, RPA, and DNA polymerase $\alpha$. Mol. Cell 5: 617-627.

Walter, J., Sun, L., and Newport, J. 1998. Regulated chromosomal DNA replication in the absence of a nucleus. Mol. Cell 1: 519-529.

Weinreich, M. and Stillman, B. 1999. Cdc7p-Dbf4p kinase binds to chromatin during $S$ phase and is regulated by both the APC and the RAD53 checkpoint pathway. EMBO J. 18: 5334-5346.

Yanow, S.K., Gold, D.A., Yoo, H.Y., and Dunphy, W.G. 2003. Xenopus Drf1, a regulator of Cdc7, displays checkpoint-dependent accumulation on chromatin during an S-phase arrest. J. Biol. Chem. 278: 41083-41092.

Yoshizawa-Sugata, N., Ishii, A., Taniyama, C., Matsui, E., Arai, K.I., and Masai, H. 2005. A second human Dbf4/ASK-related protein, Drf1/ ASKL1, is required for efficient progression of $\mathrm{S}$ and $\mathrm{M}$ phases. J. Biol. Chem. 280: 13062-13070. 


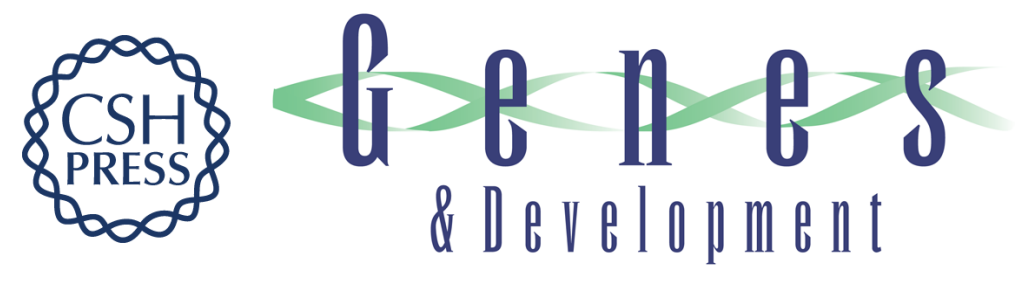

\section{Cdc7-Drf1 is a developmentally regulated protein kinase required for the initiation of vertebrate DNA replication}

Tatsuro S. Takahashi and Johannes C. Walter

Genes Dev. 2005, 19:

Access the most recent version at doi:10.1101/gad.1339805

Supplemental http://genesdev.cshlp.org/content/suppl/2005/09/19/19.19.2295.DC1
Material

References This article cites 34 articles, 20 of which can be accessed free at:

http://genesdev.cshlp.org/content/19/19/2295.full.html\#ref-list-1

License

Email Alerting Receive free email alerts when new articles cite this article - sign up in the box at the top

Service right corner of the article or click here.

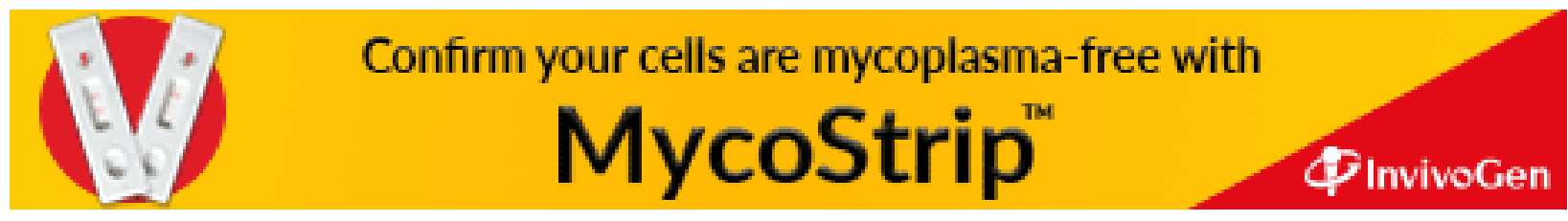

